\title{
IGUALDAD, DIFERENCIA: GENEALOGÍAS FEMINISTAS
}

\author{
ArÁnZAZu HdeZ. Piñero \\ Universidad de Zaragoza
}

Recibido: 01/03/2010

Aceptado: 08/03/2010

\begin{abstract}
Resumen
¿A qué o a quién desean igualarse las mujeres?, se interroga la pensadora de la diferencia sexual Luce Irigaray. ¿Por qué no a sí mismas?, sugiere. Orientada por estas preguntas irigarianas, esbozaré una genealogía del pensamiento y la práctica de la diferencia sexual a través, fundamentalmente aunque no sólo, de la obra de la propia Irigaray y de la Librería de Mujeres de Milán. A lo largo de este recorrido, consideraré la práctica política de la diferencia sexual como una práctica de libertad y sugeriré que la libertad femenina, su sentido y sus posibilidades, constituye uno de los nudos de conflicto del feminismo contemporáneo. Para finalizar, apostaré por la potencial fecundidad de los conflictos en el feminismo.
\end{abstract}

Palabras clave: diferencia sexual, igualdad, mediación sexuada, libertad femenina y política.

\begin{abstract}
«Whom or what do women want to be equal to?» asks herself Luce Irigaray, the thinker of the sexual difference. «Why not to themselves?» she proposes. Oriented by these irigaraian questions, I am going to present a genealogy of the thought and practice of the sexual difference through the works of Irigaray and the Women's Bookshop of Milan. I am going to describe the political practice of the sexual difference as a practice of freedom and will suggest that feminine freedom, its meaning and its possibilities constitute one of the cores of the conflict in contemporary feminism. I will end my paper supporting the potential fecundity of the conflicts in feminism.
\end{abstract}

Keywords: sexual difference, equality, sexuated mediation, feminine freedom and politics.

Feminismo/s 15, junio 2010, pp. 75-94 

Preguntada por las implicaciones políticas de su planteamiento filosófico, la pensadora de la diferencia sexual Luce Irigaray señala:

El primer interrogante a plantear es, entonces: ¿cómo pueden las mujeres analizar su explotación, inscribir sus reivindicaciones, en un orden prescrito por lo masculino? ¿Es posible una política de las mujeres en tal orden? ¿Qué transformaciones exigiría en el funcionamiento político mismo? ${ }^{1}$

Consciente de la complejidad de la problemática, la autora apunta: «Pero estas cuestiones son complejas», ya que "no se trata, evidentemente, de que las mujeres renuncien a la igualdad de los derechos sociales». Así pues, «¿cómo articular la doble «reivindicación»: de igualdad y de diferencia?» ${ }^{2}$

El feminismo de la diferencia sexual ha tratado de responder a este interrogante a partir de una profunda crítica a la noción de igualdad, indagando en el significado de esta noción y en sus presupuestos filosófico-políticos: es decir, no sólo considerando las dificultades de realización de la igualdad sino, sobre todo, reflexionando en torno al principio mismo de igualdad, al modelo que éste presupone y que, por lo tanto, no cuestiona, a saber, un modelo masculino-falogocéntrico que se presenta como neutro y universal. De aquí que la crítica a la idea de igualdad haya sido elaborada por las feministas de la diferencia sexual en términos de crítica a la asimilación u homologación de las mujeres a un modelo masculino, prestando especial atención al sutil y persistente desplazamiento entre igualdad e identidad ${ }^{3}$. Irigaray ha planteado el nudo de la discusión del siguiente modo:

1. IRIGARAY, Luce. «Poder del discurso, subordinación de lo femenino». En Ese sexo que no es uno. Madrid, Saltés, 1982, p. 77.

2. Ibíd., pp. 77-78.

3. Entre finales de la década de los ochenta y principios de los noventa, un modo de abordar el debate igualdad-diferencia fue el de señalar la falsa oposición entre ambos términos: igualdad no se opone a diferencia, sino a desigualdad, y diferencia a identidad. Cf., a modo de ejemplo: AMORÓs, Celia. «Igualdad e identidad». En A. Valcárcel (comp.), El concepto de igualdad. Madrid, Pablo Iglesias, 1994, pp. 29-48. No obstante, a mi juicio, tal precisión no agota la discusión, sino que la resitúa, pues, permanecen abiertas dos cuestiones: cómo pensar el término de comparación que implica el concepto de igualdad y cómo articular la relación identidad-diferencia. En ambos casos, está en juego la cuestión de las mediaciones. En este sentido, cf.: MURARO, Luisa. «Oltre l'uguaglianza». 
Reclamar la igualdad, como mujeres, me parece la expresión equivocada de un objetivo real. Reclamar la igualdad implica un término de comparación. ¿A qué o a quién desean igualarse las mujeres? ¿A los hombres? ¿A un salario? ¿A un puesto público? ¿A qué modelo? ¿Por qué no a sí mismas? ${ }^{4}$

En lo que sigue, orientada por estas preguntas irigarianas, esbozaré una genealogía del pensamiento y la práctica de la diferencia sexual a través, fundamentalmente aunque no sólo, de la obra de la propia Irigaray y de la Librería de Mujeres de Milán. Tres objetivos animan mi exposición: en primer lugar, mostrar el sentido filosófico y político de la crítica al modelo en el que se inscribe la noción de igualdad. En segundo lugar, abordar la propuesta política de articular mediaciones sexuadas como forma de vinculación y elaboración femenina de mundo. Y, por último, dar cuenta de la riqueza y diversidad del feminismo de la diferencia sexual. A lo largo de este recorrido, consideraré la práctica política de la diferencia sexual como una práctica de libertad y sugeriré que la libertad femenina, su sentido y sus posibilidades, constituye uno de los nudos de conflicto del feminismo contemporáneo. Para finalizar, apostaré por la potencial fecundidad de los conflictos en el feminismo.

\section{1. ¿A qué o a quién desean igualarse las mujeres?}

En Ese sexo que no es uno Irigaray afirma:

...lo femenino no tiene lugar (...) más que en el interior de modelos y de leyes promulgados por sujetos masculinos. Lo que implica que no existen realmente dos sexos, sino uno sólo. Una sola práctica y representación de lo sexual. Con su historia, sus necesidades, sus reversos, sus faltas, su/sus negativos... cuyo soporte es el sexo femenino ${ }^{5}$.

De este modo da cuenta de la estructura teórica de la indiferencia sexual. La indiferencia sexual ha operado, siguiendo a la autora, como presupuesto de toda representación del sujeto y de todo orden sociosimbólico. Según la lógica de la indiferencia sexual, sólo existe un sexo, el masculino, que es el modelo, mientras que el sexo femenino se encuentra siempre determinado en función del modelo masculino. "Lo "femenino" -sostiene Irigaray- es descrito siempre como defecto, atrofia, reverso del único sexo que monopoliza el valor: el sexo masculino ${ }^{6}$. Lo femenino está definido por y juega un papel especular. Esto es lo que la filósofa ha denominado «especula(riza)ción de lo femenino»:

En Diótima, Oltre l'uguaglianza. Le radici femminili dell'autorità. Nápoles, Liguori, 1995, pp. 105-132.

4. IRIgaraY, Luce. «Iguales o diferentes». En Yo, tú, nosotras. Madrid, Cátedra, 1992, p. 9.

5. Irigaray, Luce. «Così fan tutti». En Ese sexo... Op.cit., p. 85.

6. IrIgaray, Luce. «Poder del discurso...» En Ese sexo... Op.cit., p. 68. 
la mujer y lo femenino sirven de espejo para que el sujeto (masculino) pueda disponer de su autorrepresentación. La especula(riza)ción de lo femenino funciona, pues, como la condición de posibilidad del sujeto masculino ${ }^{7}$; a tal punto que la expresión «sujeto masculino» resultaría una redundancia.

La lógica de la indiferencia sexual articula el orden social y simbólico: los hombres establecen entre sí un vínculo sociosimbólico a través del intercambio de mujeres. O dicho de otro modo, los hombres pactan entre sí el acceso a las mujeres, que aparecen como monedas y mercancías en el intercambio masculino. «Los hombres comercian con ellas, pero sin intercambiar con ellas» ${ }^{8}$. Es la circulación de las mujeres entre los hombres lo que funda el orden social, cultural, sexual y político; el «orden a secas» ${ }^{9}$. A este vínculo homosocial, Irigaray lo denomina hom(m)osexual. La autora hace un juego de palabras con homo y homme, «igual»y «hombre», donde la duplicación de la «m» en «hom $(\mathrm{m})$ osexualidad» convierte esta homosexualidad en sexualidad masculina (homosexualité y hommesexualité), una suerte de hombresexualidad, en tanto que sexualidad de lo mismo: la representación del hombre y su deseo. Así, analiza el estatuto de las mujeres como mercancías en un orden prescrito por la homosocialidad, o, en términos irigarianos, hom(m)osexualidad.

El uso, el consumo y la circulación de los cuerpos de las mujeres constituyen la «condición de posibilidad de la socialidad y de la cultura», no obstante, «permanecen como una «infraestructura» desconocida de su elaboración». Gran parte del magnífico trabajo de Irigaray consiste en desvelar el funcionamiento de este mecanismo, en mostrar cómo «la materia sexuada mujer» ${ }^{10}$ opera como la «infraestructura» oculta de toda sociedad patriarcal. En este marco, las únicas relaciones posibles entre mujeres son o bien de rivalidad o bien de identificación con el modelo masculino, en el caso del lesbianismo. De rivalidad, habida cuenta de que el valor de las mujeres depende exclusivamente de aquel que le conceden los hombres en las relaciones que establecen entre ellos. O de identificación con el hombre, en el caso del lesbianismo, ya que el deseo se halla prescrito por lo masculino. Como insiste Irigaray, «no se trata jamás de la mujer en estos enunciados» ${ }^{11}$, sino de su construcción falogocéntrica en términos de carencia y especularidad. Así, en este or-

7. Cf. IrigaraY, Luce. Speculum. Espéculo de la otra mujer. Madrid, Saltés, 1978 (orig. 1974).

8. IRIGARAY, Luce. «El mercado de las mujeres». En Ese sexo... Op.cit., p. 163. La autora elabora este análisis en discusión con la tesis del intercambio de mujeres de Lévi-Strauss.

9. Ibíd., p. 161.

10. Ibíd., p. 161.

11. IRIGARAY, Luce. «Poder del discurso...». En Ese sexo... Op.cit., p. 68.

Feminismo/s 15, junio 2010, pp. 75-94 
den, el deseo femenino y el deseo lesbiano aparecen como irrepresentados e irrepresentables ${ }^{12}$.

Al presuponer que el deseo responde a su construcción falogocéntrica, esto es, al deseo masculino, al que Irigaray se refiere como «deseo de lo mismo», el deseo de las mujeres queda regulado por esta prescripción, es decir, las mujeres desearían lo mismo que desean los hombres. En este sentido, observa la autora, «el interés que las mujeres pueden tener por la sociedad corresponde solamente, por cierto, al deseo de tener poderes iguales a los que obtiene el sexo masculino» ${ }^{13}$. Esto nos sitúa ante dos cuestiones, estrechamente relacionadas: por un lado, la de interrogarnos por la configuración del deseo, y las subjetividades que tal configuración constituye, o, en otras palabras, preguntarnos por el deseo de las mujeres en términos diversos al de su constitución falogocéntrica. La filósofa articula esta posibilidad a lo largo de su trabajo: la conformación de una subjetividad femenina autónoma a partir de la heterogeneidad del deseo femenino. La pensadora invita a las mujeres a explorar su alteridad sin someterla a la jerarquía instaurada por el falogocentrismo, donde lo femenino se define por negación, como lo no-masculino. En la lógica de la indiferencia, la diferencia sexual es concebida en términos jerárquicos, por lo que supone siempre desigualdad. En cambio, Irigaray propone pensar lo femenino y la diferencia sexual sin jerarquía, lo que requiere un pensamiento nuevo: el pensamiento de la diferencia sexual. Propuesta que podría resumirse en su idea de ser otras sin ser segundas: ser reconocidas realmente como otras, irreductibles al sujeto masculino ${ }^{14}$.

Y, por otro lado, la de dar cuenta de una gran paradoja: demandar, como mujeres, la inclusión en un orden cuya condición de posibilidad es la exclusión-apropiación del cuerpo de las mujeres. Ésta es la razón por la que Irigaray se pregunta, como señalaba al principio, por las transformaciones que exigiría el funcionamiento político para que fuese posible una política de las mujeres. Y el motivo por el que apuesta por un movimiento de las mu-

12. De aquí la afirmación irigariana de que «no existirá, por tanto, homosexualidad femenina, sino una única hommo-sexualidad por medio de la cual (...) se solicitará de ella [la mujer] que enarbole para el hombre el deseo de lo mismo». IRIGARAY, Luce. Speculum... Op.cit., p. 114. He abordado ampliamente esta cuestión en: HDEZ. PIÑERO, Aránzazu. Amar la fluidez. Teoría feminista y subjetividad lesbiana. Zaragoza, Eclipsados, 2009, pp. 19-83.

13. IRIgaray, Luce. «Poder del discurso...». En Ese sexo... Op.cit., p. 68.

14. En discusión con la comprensión de la alteridad en Simone de Beauvoir. Cf. IRIGARAY, Luce. «La questione dell'altro». En La democrazia comincia a due. Turín, Bollati Boringhieri, 1994, pp. 109-124. 
jeres que cuestione las formas y la naturaleza de la vida política ${ }^{15}$. La autora formula su potente interrogante como sigue:

... sin la explotación de las mujeres, ¿qué sería del orden social? ¿Qué modificaciones sufriría éste si las mujeres salieran de su condición de mercancías (...) y tomaran parte en la elaboración y funcionamiento de los intercambios? Pero no reproduciendo, imitando, los modelos «falocráticos» que constituyen hoy en día la ley, sino socializando de otra manera la relación con la naturaleza, con la materia, con el cuerpo, con el lenguaje, con el deseo ${ }^{16}$.

Esto es justamente lo que ha ocurrido y ocurre, lo que el feminismo ha posibilitado: la pérdida de credibilidad del patriarcado, de sus formas sociosimbólicas y la apertura femenina de nuevas formas. La fuerza de esta ruptura, como bien ha señalado Irigaray, entre otras, procede de la quiebra con respecto al orden dado que ha supuesto la emergencia de los grupos de mujeres y las formas políticas que el separatismo femenino ha puesto en juego. La fuerza de lo que Irigaray ha denominado el «entre-mujeres» ${ }^{17}$, el establecimiento de relaciones significativas entre mujeres para dar un sentido nuevo al mundo así como a su existencia en el mundo. Recientemente, en un hermoso artículo, la filósofa belga Françoise Collin ha descrito esta ruptura como el paso «del intercambio de mujeres al intercambio entre mujeres ${ }^{18}$.

Una vez desvelado el vínculo homosocial como fundante de todo orden (patriarcal), la apuesta irigariana para disolver las mediaciones masculinas y hacer emerger la diferencia sexual se articula, inicialmente, en torno a la bella imagen de las «genealogías femeninas» ${ }^{19}$. La metáfora genealógica evoca y motiva la posibilidad de que cada mujer se inscriba en una filiación femenina, reconociendo a las mujeres que vinieron al mundo antes que ella y a las que han llegado después. Las feministas italianas de la diferencia sexual, en particular, la Librería de Mujeres de Milán y, posteriormente, la comunidad filosó-

15. Cf., por ejemplo, Irigaray, Luce. «Poder del discurso...» y «Preguntas». En Ese sexo... Op.cit., pp. 77-78 y pp. 153-156.

16. IRIGARAY, Luce. «El mercado...». En Ese sexo... Op.cit., p. 178.

17. Cf., por ejemplo, IrigaraY, Luce. «Preguntas». En Ese sexo... Op.cit., pp. 151-153.

18. Cf. Collin, Françoise. «De l'échange des femmes à l'échange entre femmes». per amore del mondo, primavera 2008, <http://www.diotimafilosofe.it/riv_online.php>, consultado el 19-01-2009. Una muestra de la fecundidad de esta ruptura y de las posibilidades abiertas lo constituye, a mi juicio, el recorrido de la política de la diferencia sexual en Italia: cf. LIBRERÍA DE MUJERES DE MILÁN. No creas tener derechos. La generación de la libertad femenina en las ideas y vivencias de un grupo de mujeres. Madrid, horas y HORAS, 2004; y La cultura patas arriba. Selección de la Revista Sottosopra 1973-1996. Madrid, horas y HORAS, 2006.

19. Cf. IRIGARAY, Luce. «El cuerpo a cuerpo con la madre». En El cuerpo a cuerpo con la madre. El otro género de la naturaleza. Otro modo de sentir. Barcelona, La Sal, 1985, pp. 5-17.

Feminismo/s 15, junio 2010, pp. 75-94 
fica femenina Diótima, han trabajado creativamente inspiradas en esta noción irigariana, indagando en la necesidad de establecer mediaciones femeninas.

\section{2. ¿Por qué no a sí mismas?}

¿A qué o quién desean igualarse las mujeres?, se pregunta Irigaray. ¿Por qué no a sí mismas?, sugiere. ¿Cómo podemos entender este «sí mismas»?, ¿la subjetividad a la que el «sí mismas» alude? Para tratar de responder a este interrogante, abordaré la reflexión acerca de las mediaciones femeninas elaborada por la Librería de Mujeres de Milán en su ya clásico No creas tener derechos. La generación de la libertad femenina en las ideas y vivencias de un grupo de mujeres, texto de escritura colectiva que narra las experiencias políticas de diversos grupos de mujeres de Milán, principalmente, entre 1966 y 1986.

Dado que las mediaciones sociales y simbólicas existentes respondían a una construcción falogocéntrica del mundo, la posibilidad de inscribir social y simbólicamente la diferencia sexual requería la elaboración de mediaciones femeninas. La práctica política de las feministas italianas de la diferencia sexual se articula en torno a la propuesta de «sexuar las relaciones sociales»:

Sexualizar las relaciones sociales quiere decir quitarles su aparente neutralidad y mostrar que en las maneras socialmente corrientes de relacionarse con sus semejantes, una mujer no se encontraba íntegramente ni con su placer ni con sus capacidades. Porque las motivaciones para implicarse en el juego social, como también sus reglas y sus ganancias, están todas, directa o indirectamente, dirigidas a la masculinidad, están hechas para suscitarla o para gratificarla. Es difícil involucrarse en una situación en la que el propio placer es siempre una incógnita ${ }^{20}$.

Para crear condiciones en las que el deseo y el placer femeninos encontrasen lugar social era preciso otorgar autoridad a los medios inventados por el movimiento de mujeres y reconocer a las mujeres como fuente de autoridad y legitimidad sociosimbólica. Es decir, la apuesta consiste en mostrar la necesidad de dar representación social y simbólica a las relaciones libres entre mujeres y generar estas mediaciones como práctica política ${ }^{21}$. La política de la diferencia sexual se presenta, pues, como una práctica de libertad.

20. LIBRERÍA DE MUJERES DE MILÁN. «Más mujeres que hombres. Sottosopra verde (enero, 1983)». En La cultura... Op.cit., p. 115.

21. Para un análisis de la noción de práctica en el pensamiento italiano de la diferencia sexual y en el feminismo angloestadounidense: cf. ZAMBONI, Chiara. "Una contesa filosofica e politica sul senso delle pratiche». per amore del mondo, otoño 2006, <http:// www.diotimafilosofe.it/riv_online.php>, consultado el 25-05-2007. 
Ahora bien, la elaboración de mediaciones femeninas, la constitución de «un mundo común de las mujeres» ${ }^{22}$, en la bella formulación de Adrienne Rich, no implica la asunción de una suerte de identidad homogénea de las mujeres, ya dada o susceptible de ser definida, sino, por el contrario, demanda la puesta en juego de la disparidad entre mujeres, sacando «a la luz deseos y necesidades subjetivas enraizadas en historias individuales diversas $»^{23}$, contando con «las múltiples experiencias, posibilidades y diversidad $»^{24}$ que se dan entre las mujeres. Es lo que las mujeres de la Librería de Milán han llamado la práctica de la disparidad, que late en el corazón de la práctica de las relaciones entre mujeres o affidamento, relación en la que una mujer confía en otra u otras a la hora de establecer sus vínculos con el mundo ${ }^{25}$. De este modo, las feministas italianas de la diferencia sexual abordan un problema doble, también indicado por Irigaray: por un lado, la indiferenciación entre hombres y mujeres y, por otro, la indiferenciación entre mujeres.

La indiferencia entre hombres y mujeres (la indiferencia sexual a la que se refería Irigaray) sitúa a las mujeres en un mundo constituido por un pacto

22. Expresión retomada por las mujeres de la Librería de Milán: cf. «Más mujeres...». En La cultura... Op. cit., p. 119. Rich planteaba la reflexión siguiente: «Las mujeres, a la vez, han tenido y no han tenido un mundo común. El solo hecho de compartir la opresión no constituye un mundo común». Cf. RicH, Adrienne. «Condiciones de trabajo: el mundo común de las mujeres (1976)». En Sobre mentiras, secretos y silencios. Barcelona, Icaria, 1983, pp. 240-253. Con respecto a la noción de «lo común», Françoise Collin ha distinguido, muy oportunamente, lo común y lo homogéneo: lo común no implica homogeneidad, sino, por el contrario, pluralidad de perspectivas. Lo que señala a partir de su lectura de la noción arendtiana de mundo común; noción que otras pensadoras de la diferencia sexual, como Diana Sartori, pondrán también en juego. Cf.: Collin, Françoise. «De l'échange...» Op.cit.

23. LIBRERÍA DE MUJERES DE MILÁN. No creas... Op. cit., p. 90.

24. Ibíd., p. 120.

25. En este abordaje de las diferencias entre mujeres, la disparidad no se reduce al registro de la desigualdad que, por otra parte, las autoras no niegan. En el ámbito feminista angloestadounidense este debate se ha planteado fundamentalmente en términos de desigualdad. Desde principios de la década de los noventa, se discute en torno a cómo podrían distinguirse las diferencias producidas por la desigualdad de aquéllas que serían objeto de reconocimiento. A modo de ejemplo, cf: FRASER, Nancy. Iustitia Interrupta. Reflexiones críticas desde la posición "postsocialista». Santafé de Bogotá, Universidad de los Andes, 1997; y Young, Iris. La justicia y la política de la diferencia. Madrid, Cátedra, 2000. Para una comparación del debate italiano con el angloestadounidense: cf. ZeRILLI, Linda. El feminismo y el abismo de la libertad. Buenos Aires, FCE, 2008, pp. 213-224. Para una lectura desde la diferencia sexual en discusión con las teorías de género: BRAIDOTti, Rosi. Sujetos nómades. Corporización y diferencia sexual en la teoría feminista contemporánea. Buenos Aires, Paidós, 2000, pp. 165-205. Comparto, en gran medida, el planteamiento de Braidotti, para quien las diferencias entre mujeres son constitutivas de la noción de diferencia sexual, y no exteriores ni opuestas a la misma.

Feminismo/s 15, junio 2010, pp. 75-94 
masculino en el que las mujeres son objetos del pacto y las aboca a una difícil paradoja: ser, al mismo tiempo, objetos y sujetos del pacto social; o mejor, querer ser sujetos en una situación cuya condición de posibilidad radica en haberlas convertido en objetos (como he señalado, siguiendo a Irigaray, en el epígrafe anterior $)^{26}$. En estas circunstancias, las mujeres aparecen como idénticas entre sí, sin posibilidad de singularizarse en tanto que tales; puesto que, como ha observado Irigaray, aparecen como el «otro de lo Mismo» o, como ha indicado Celia Amorós, desde otra perspectiva y con otros propósitos, como «idénticas», el espacio de las mujeres se ha configurado como el «espacio de las idénticas» ${ }^{27}$. De manera que la doble indiferenciación a la que aludía se halla íntimamente relacionada. Y éste es un nudo que las feministas italianas de la diferencia sexual deshacen magistralmente: la indiferenciación entre mujeres resulta de la indiferenciación entre hombres y mujeres, entendiendo por indiferenciación la neutralización o la cancelación de la diferencia sexual. En este sentido afirman:

En vano buscaremos en las reflexiones masculinas seculares sobre la relación entre individuo y colectividad una respuesta al problema, que se le plantea a toda mujer, de compaginar su voluntad de distinción personal con la demanda que le transmiten sus semejantes pidiéndole que no se separe del común de las mujeres. El orden simbólico-social, pensado por los hombres como universal, no da respuesta a este problema, ni justa ni injusta, ni aceptable ni mejorable. Lo que pasa entre mujeres, vida, palabras, sentimientos, sexualidad, amor, saber, todo quedaba abandonado a su aire y únicamente se regulaba cuando interfería con la manera en que se han regulado las relaciones de los hombres entre sí.

En este punto ciego del pensamiento político está la prueba de que el pacto social fue concebido teniendo presente la experiencia masculina ${ }^{28}$.

¿Cómo abordar, entonces, la singularidad de las mujeres? Las feministas de la Librería de Mujeres de Milán invitan a las mujeres a «romper por la mitad el pacto social y medirse con el mundo sobre la base de su diferencia» ${ }^{29}$.

La pregunta, no obstante, es insistente, e, incluso, insidiosa. Insistente, en la medida en que, tal y como observan con perspicacia las autoras, el deseo de singularidad de cada mujer se encuentra ante la demanda de comunidad del resto de las mujeres (la petición de que «no se separe del común de las mujeres»). E insidiosa, habida cuenta de que, históricamente, la política feminista

26. Desde otra perspectiva, si bien manteniendo esta tesis central: cf. PATEMAN, Carole. El contrato sexual. Barcelona, Anthropos, 1995.

27. Cf. Amorós, Celia. «Igualdad...» Op.cit., pp. 29-48.

28. LIBRERÍA DE MUJERES DE MILÁN. No creas... Op.cit., pp. 209-210.

29. Ibid., p. 223. 
se ha articulado a partir de constituir a las mujeres en tanto que «identidad» política. Pero, ¿en qué términos se ha constituido esta identidad política? Resumidamente, podríamos decir que en términos de una opresión común. Las mujeres de la Librería de Milán reflexionan largamente acerca de estas figuraciones de la identidad femenina. Y considero que la práctica de la disparidad y la libertad femenina son sus potentes respuestas a esta cuestión, que, desde mi punto de vista, atraviesa el debate en torno a la igualdad y la diferencia tal y como se ha dado, al menos, en los últimos treinta años.

Si consideramos que la categoría «mujeres» tiene sentido única y exclusivamente en términos de la opresión sufrida, entonces la identidad puesta en juego es una identidad reactiva y, en consecuencia, se comprende el deseo de abandonar y/o eliminar esta categoría (p.e., Monique Wittig o Gayle Rubin $)^{30}$. Pero, ¿podríamos pensarla de otro modo? Las feministas italianas de la diferencia sexual nos invitan a ello al proponerse y proponernos pensar la práctica política feminista en términos de libertad. Recientemente, la autora estadounidense Linda Zerilli ha hecho una sugerente lectura en este sentido ${ }^{31}$.

Las mujeres de la Librería de Milán no reducen la cuestión de la libertad a la liberación de la opresión, sino que su preocupación central es la libertad entendida como capacidad de fundar nuevas formas de asociación política, que no pueden pensarse independientemente de la diferencia sexual. Donde ésta no ha de ser destruida ni trascendida, sino, resimbolizada, transformándola «de causa social de no-libertad en principio de nuestra libertad $»^{32}$.

Siguiendo a Zerilli, pensar la libertad no únicamente en términos de liberación de la opresión nos permite abordar y deshacer lo que la filósofa estadounidense Wendy Brown ha denominado la «paradoja de la libertad», según la cual el sujeto es instado a reiterar las mismas normas sociales que lo constituyen como sujeto/sujetado. Sin esta reiteración el sujeto no tendría sensación de su propia realidad y carecería de existencia social. En palabras de la autora:

....al surgir como una protesta contra la marginación y la subordinación, la identidad politizada se vincula a su propia exclusión tanto porque su existencia misma como identidad se basa en esta exclusión como porque la formación de la identidad en el lugar de la exclusión, como exclusión, aumenta o «altera la dirección del sufrimiento» que entraña la subordinación o la marginación al encontrar para él un lugar de culpa. Pero al hacerlo instala su dolor

30. Cf. WitTig, Monique. El pensamiento heterosexual y otros ensayos. Madrid, EGALES, 2006; y RUBIN, Gayle. «Tráfico de mujeres: notas sobre la «economía política» del sexo». En M. Lamas (comp.), El género: la construcción cultural de la diferencia sexual. México, PUEG/Ángel Porrúa, 1996.

31. Cf. Zerilli, Linda. Op.cit., pp. 187-238.

32. LIBRERÍA DE MUJERES DE MILÁN. No creas... Op.cit., p. 185.

Feminismo/s 15, junio 2010, pp. 75-94 
en la historia irredenta que subyace al fundamento mismo de su reclamo político en su exigencia de reconocimiento como identidad ${ }^{33}$.

Así, las «mujeres» se constituirían como una identidad herida, a partir de lo que Brown llama «vínculos heridos», es decir, «vínculos con la no libertad», con las heridas históricas que han constituido la identidad femenina ${ }^{34}$. Y es en este sentido en el que podemos interpretar la afirmación de las mujeres de la Librería de Milán de que «mientras una mujer pida reparaciones, obtenga lo que obtenga, nunca conocerá la libertad» ${ }^{35}$. Al proponer transformar la diferencia sexual de «causa social de no-libertad en principio de nuestra libertad $»^{36}$, las italianas tratan de deshacer esta paradoja mediante «los rasgos creativos y disruptivos de la libertad política y la práctica cotidiana de la construcción-de-mundo» ${ }^{37}$.

¿De qué libertad hablamos? De una libertad que procede de «la atribución de autoridad y valor a otra mujer en las relaciones con el mundo» ${ }^{38}$, lo que posibilita una «estructura simbólica de mediación ${ }^{39}$, es decir, una mediación sexuada en femenino capaz de poner a las mujeres en relación consigo mismas ( «para darse autoridad y valor a una misma, a la propia experiencia, a los propios deseos $»^{40}$ ), con las otras y con el mundo. O, en otras palabras, «el simple reconocimiento en la relación entre mujeres es el acto sobre el cual se fundamenta en la práctica la libertad femenina ${ }^{41}$. Simple y, al mismo tiempo, difícil, porque, como señalan las mujeres de la Librería de Milán, no había lugar para las relaciones libres entre mujeres en las representaciones sociales, ya desveladas como masculinas y presentadas como neutras. A este respecto, subrayan las autoras, no se trataba tanto de que no existiesen experiencias de libertad por parte de las mujeres, sino que estas experiencias de libertad no conseguían traducirse en ganancias ni para sí mismas ni para el resto de las

33. BRown, Wendy. States of Injury: Power and Freedom in Late Modernity. Princeton, Princeton University Press, 1995, pp. 73-74; citada en ZeriLli, Linda. Op.cit., p. 201. En el contexto angloestadounidense, se da, desde mediados de la década de los ochenta, un interesante debate acerca de si la demanda de reconocimiento se ha de formular necesariamente en términos de política de la identidad. He abordado parte de esta discusión en: HDEZ. Piñero, Aránzazu. Op.cit., pp. 87-114.

34. BROwn, Wendy. Op.cit., p. xii; citada en ZeRILli, Linda. Op.cit., p. 200.

35. Modifico la traducción: LIBRERÍA DE MUJERES DE MILÁN. No creas... Op.cit., pp. 196-197. Cf. Non credere di avere dei diritti. Turín, Rosenberg \& Sellier, 1987, p. 156.

36. Ibíd., p. 185.

37. ZERILLI, Linda. Op. cit., p. 198.

38. LIBRERÍA DE MUJERES DE MILÁN. No creas... Op.cit., p. 168.

39. Ibid., p. 163.

40. Ibid., p. 168.

41. Ibid., p. 199.

Feminismo/s 15, junio 2010, pp. 75-94 
mujeres, debido a la falta de representación simbólica, o, mejor, a la ausencia de una representación simbólica adecuada. De aquí su apuesta por «trabajar políticamente sobre lo simbólico ${ }^{42}$. Así, «dando nombre y forma social a lo que, sin nombre y sin forma, sucedía entre mujeres ${ }^{43}$, dotan de significación social y simbólica a lo que aparecía, inicialmente, como «el punto ciego del pensamiento político ${ }^{44}$. Este trabajo político sobre lo simbólico hace posible dar un sentido distinto al orden dado, subvirtiéndolo, reordenándolo y, de esta manera, transformándolo. «La subversión -sostienen- atañe al modo en que las cosas se combinan entre sí, esto es, a su sentido. Hay combinaciones nuevas que quitan sentido a la realidad dada y de este modo la cambian, deteriorándola»; ya que al «pensar y aplicar las nuevas combinaciones» ${ }^{45}$, la realidad dada deja de aparecer como la única dotada de sentido y valor.

Así tiene lugar la libertad femenina, «en la nueva combinación de relaciones libres entre mujeres, a través de palabras y de gestos de la vida cotidiana ${ }^{46}$. En esta práctica política son las mismas mujeres las que garantizan la libertad femenina, pues, afirman las autoras, «la libertad es el único medio para alcanzar la libertad» ${ }^{47}$.

La libertad no es pensada, por tanto, como una meta remota, ni tampoco se reduce a la libertad negativa ni a los derechos individuales garantizados por la ley; sino que es concebida como una potencia que genera libertad y mundo al mismo tiempo. La libertad es entendida, entonces, como «algo» que se crea en la práctica cotidiana a través de su ejercicio, en el reconocimiento y agradecimiento de una mujer hacia las otras mujeres como fundantes de su vinculación con el mundo ${ }^{48}$. La libertad, este «algo», no se tiene como se tiene una posesión, no se tiene, en definitiva; sino que surge en y de la relación. Es, pues, una libertad relacional. Como ha dicho Diana Sartori, quien forma parte de la comunidad filosófica femenina Diótima, se trata de «una libertad con»: «una libertad que existe en relación. O, mejor, es una práctica de libertad

42. Ibíd., p. 157. Cf. MuRARO, Luisa. El orden simbólico de la madre. Madrid, horas y HORAS, 1994.

43. Ibíd., p. 227.

44. Ibíd., p. 210.

45. Ibíd., p. 182.

46. Ibid.., p. 183.

47. Ibíd., p. 228. Cf. también, ibíd., p. 221.

48. Ibíd., p. 214. Para la idea de la libertad como creación: cf. Muraro, Luisa. «Feminismo y política de las mujeres». Duoda, 28 (2005), pp. 39-47.

Feminismo/s 15, junio 2010, pp. 75-94 
entendida como práctica de relación ${ }^{49}$. Las mujeres de la Librería de Milán concluyen:

La libertad femenina, en suma, no se obtiene con la admisión en la sociedad masculina ni como resultado de una reivindicación frente a ella, sino a través del contrato elemental en virtud del cual una mujer intercambia con otras semejantes a ella el reconocimiento de la propia existencia contra la aceptación significada de la común pertenencia al sexo femenino ${ }^{50}$.

De manera que la significación libre de la propia existencia en la relación de affidamento permite diluir «la aceptación significada de la común pertenencia al sexo femenino», es decir, los significados dados a la diferencia sexual, y hace emerger la diferencia sexual como significante y como «fuente inagotable de significados siempre nuevos $»^{51}$. Así entendida, la diferencia sexual no depende de contenidos específicos, sean éstos valores éticos o cualquiera otros, no especifica contenido alguno, sino que hace significante la diferencia sexual en tanto "diferencia irreductible $»^{52}$, que queda abierta al libre juego de la significación.

Llegadas a este punto, quisiera retomar la pregunta irigariana con la que comenzaba este epígrafe: «¿a qué o a quién desean igualarse las mujeres? (...) ¿Por qué no a sí mismas?» Y mi interrogación acerca del significado de este «sí mismas», ya que considero que es ahora, tras el recorrido hecho junto con las italianas, que podemos comprender mejor el sentido de la subjetividad a la que este «sí mismas» refiere. El «sí mismas» no surge como expresión de una identidad ya dada o susceptible de ser definida, sino que se conforma en relación abierta con las otras y el mundo, donde la transformación del mundo acaece a partir de la transformación de sí, de la relación que establece cada una con él a través de las otras, y también de los otros. Así, sostendría con Diana Sartori:

...no se trata de prohibir toda forma de afirmación para evitar caer en el «qué», en una identidad (porque esto es, en cierto modo, inevitable), sino de mantener abierta la apertura originaria del «quién» y de su calidad relacional constitutiva como centro de la acción política, pensando la identidad

49. SARTORI, Diana. «Libertad «con». La orientación de las relaciones». Duoda, 26 (2004), p. 105.

50. LIBRERÍA DE MUJERES DE MILÁN. No creas... Op.cit., p. 216.

51. Ibíd., p. 192.

52. Ibíd., p. 189. Cf. Ibíd., pp. 189-192. Con respecto a la comprensión de la diferencia sexual, cabe señalar una distancia importante entre el feminismo de la diferencia sexual y el feminismo de la diferencia angloestadounidense, como ha hecho notar, entre otras, la filósofa británica Alison Stone. Cf. STONE, Alison. An Introduction to Feminist Philosophy. Cambridge, Polity Press, 2007, pp. 112-139. 
no como una reificación que se da por supuesta y que tenemos que expresar, sino como un azar simbólico, donde ponemos a la vez en juego nuestro sentido y el sentido del mundo ${ }^{53}$.

Pues, como muy bien observa Rosi Braidotti y he intentado mostrar, lo que está en juego «no es lo femenino, tal como se ha codificado en el código falogocéntrico del imaginario patriarcal, sino lo femenino como proyecto, como movimiento de desestabilización de la identidad y, por lo tanto, como movimiento de devenir ${ }^{54}$.

\section{3. ¿Y los derechos?}

Pero aún cabría preguntarse: ¿y los derechos? Si, como sostienen las mujeres de la Librería de Milán, «tener interlocutoras magistrales es más importante que tener derechos reconocidos $»^{55}$, ¿qué implicaciones tiene esta afirmación con respecto a los derechos?

Es cierto que las mujeres de la Librería de Milán tienden a considerar que la vía de los derechos es una vía perdedora en la medida en que entrampa a las mujeres en, al menos, dos sentidos: por un lado, al seguir concediendo autoridad a las instituciones masculinas y no generar fuentes femeninas de autoridad; y, por otro, al no crear condiciones que eviten el fácil deslizamiento de la igualdad a la asimilación u homologación. Ahora bien, una lectura más atenta nos permitiría aproximarnos a la discusión que se ha dado y se continúa dando en torno al papel de los derechos y la ley entre diversas autoras de la diferencia sexual. Y, tal vez, de este modo replantear el debate. Por ejemplo, tal y como sugiere Tamar Pitch, preguntándonos si los derechos son simplemente insuficientes o si, más bien, constituyen un obstáculo para la libertad femenina ${ }^{56}$. O, como indica, desde otra perspectiva, Linda Zerilli interrogándonos

53. SARTORI, Diana. «Nessuno è l'autore della propia storia». En Diótima, La sapienza di partire da sé. Nápoles, Liguori, 1996, p. 46. Esta formulación surge de la lectura creativa que la autora ha venido elaborando del pensamiento de Hannah Arendt, poniendo en juego las nociones de acción, libertad, mundo y política con la diferencia sexual. También cabe señalar la filiación arendtiana de Linda Zerilli, de gran importancia a la hora de comprender el sentido de la libertad tal y como lo he planteado a lo largo del presente artículo. Cf. ARENDT, Hannah. La condición humana. Barcelona, Paidós, 2005; y ARENDT, Hannah. ¿Qué es la política? Barcelona, Paidós, 1997.

54. Braidotti, Rosi. Transposiciones. Sobre la ética nómada. Barcelona, Gedisa, 2009, p. 253.

55. LIBRERÍA DE MUJERES DE MILÁN. No creas... Op.cit., p. 22.

56. Cf. PitCH, Tamar. «La libertà femminile può pasarse per i dirritti». En A. Buttarelli y F. Giardini (comp.), Il pensiero dell'esperienza. Milán, Baldini Castoldi Dalai, 2008, p. 277. El título resume su respuesta. Para consideraciones en sentido opuesto: cf. dossier «La democracia igualitaria y la violencia contra las mujeres». Duoda, 37 (2009).

Feminismo/s 15, junio 2010, pp. 75-94 
por la forma en que los rasgos creativos y disruptivos de la libertad política y la construcción-de-mundo podrían relacionarse con la demanda o el ejercicio de la igualdad de derechos ${ }^{57}$.

Como advertía Irigaray, y no se les escapa a las feministas italianas de la diferencia sexual, estas cuestiones son complejas, pues, según la autora, «no se trata, evidentemente, de que las mujeres renuncien a la igualdad de los derechos sociales ${ }^{58}$. No obstante, como he tratado de señalar, la noción y el horizonte de la igualdad han de ser radicalmente repensados. Y estimo que es en este sentido en el que Irigaray no ha dudado en afirmar que «las mujeres reivindican sus derechos para hacer advenir su diferencia $»^{59}$. La propuesta irigariana de inscribir la diferencia sexual en la cultura y la sociedad pasa también por su inscripción en la ley. De aquí que, desde finales de la década de los ochenta, la filósofa trabaje para articular derechos sexuados como una forma de establecer «condiciones de posibilidad (...) de una cultura de dos sujetos no sometidos uno al otro $»^{60}$.

Algunas de las mujeres que forman parte de la Librería de Milán, e integrantes del grupo de mujeres juristas de Milán, recogieron y repensaron la propuesta irigariana en la misma época ${ }^{61}$. Apostando por un derecho sexuado en femenino, advertían de la vacuidad de la multiplicación de leyes y derechos «a favor» de las mujeres y se inclinaban por explorar las posibilidades de resignificación de la práctica procesal como «un instrumento de producción de nuevas normas de derecho ${ }^{62}$. Puesto que consideran que en el proceso se modifica la norma jurídica que media los intereses en conflicto, siendo ésta una práctica donde se pueden hacer jugar las relaciones entre mujeres (en primer lugar, entre la abogada y la clienta), si se toma como prius la libertad femenina.

En cambio, Irigaray ha optado claramente por la necesidad de formular nuevos derechos, derechos sexuados, que se inscriban en la ley, considerándola una mediación necesaria para la articulación social y simbólica del sujeto femenino. Dado que las mujeres han sido objetos y no sujetos de la ley,

57. Cf. Zerilli, Linda. Op.cit., pp. 198-199.

58. IRIGARAY, Luce. «Poder del discurso...» En Ese sexo... Op.cit., pp. 77-78.

59. IRIgaraY, Luce. «Preguntas». En Ese sexo... Op.cit., p. 156.

60. IRIGARAY, Luce. «De Speculum a Entre Oriente y Occidente. Luce Irigaray, 25 años de filosofía feminista de la diferencia. Entrevista». Triple Jornada, La Jornada, 2 de agosto de 1999. En www.jornada.unam.mx/1999/08/02/irigaray.htm>, consultado el 15-04-2007.

61. CAMPARI, Mariagrazia y CigARINI, Lia. «Fuente y principios de un nuevo derecho (1987)». En «Un hilo de felicidad. Sottosopra oro (enero, 1989)». En LIBRERÍA DE MUJERES DE MILÁN. La cultura... Op.cit., pp. 173-182.

62. Ibid., p. 178. 
han carecido de derechos subjetivos. Por lo que «es urgente e indispensable restituir a hombres y mujeres iguales derechos subjetivos», donde «iguales quiere decir diferentes, aunque de igual valor» $\mathrm{y}$ «subjetivos implica derechos equivalentes en los sistemas de intercambio» ${ }^{63}$. A través del concurso de la ley (aunque no sólo), la autora estima que será posible constituir «un «genérico femenino»», para que las mujeres no continúen siendo una+una+una «en ese género humano, de hecho masculino» ${ }^{64}$. Esta propuesta resulta polémica tanto para las feministas de la igualdad como para las de la diferencia sexual ${ }^{65}$. Para las primeras, porque no comparten la necesidad de articular derechos positivos para las mujeres, sino que tratan de obtener derechos iguales, cabría decir idénticos, a los de los hombres. Para las segundas, porque perciben la ley como un instrumento de sumisión al Estado.

En un bello artículo, Silvia Niccolai ${ }^{66}$, en la línea del feminismo italiano de la diferencia sexual, explora la relación entre la práctica procesal, o doctrina de la experiencia jurídica, y la propuesta de las juristas milanesas mencionadas de la práctica procesal como práctica de las relaciones entre mujeres. Argumenta la autora que la política de lo simbólico, tal y como es expuesta por la Librería de Mujeres de Milán, ha dispuesto sus figuras mediante la oposición entre el derecho como ley, sin autorización simbólica femenina, y el derecho como práctica procesal, ligada a una controversia y a una demanda de justicia, que da palabra a la diferencia femenina. De su rico texto, me gustaría recoger aquí el punto de contacto que Silvia Niccolai establece entre estas dos formas de entender el derecho al indagar la manera en que la controversia mueve y genera el derecho.

En la controversia, siguiendo a Niccolai, adquieren protagonismo la interpretación y el juicio, es decir, quien interpreta y juzga lo particular. La importancia de la interpretación y el juicio basados en lo particular me permite relacionar el análisis de Niccolai con el de Zerilli, aunque sus estudios se sitúan en perspectivas diferentes y sus objetivos difieren. La lectura que hace Zerilli de No creas tener derechos la conduce a «pensar la igualdad como un problema de juicio político antes que de «lógica argumentativa» ${ }^{67}$. Juicio, en el sentido arendtiano, es decir, aquello que requiere pensar lo particular en ausencia de

63. IRIGARAY, Luce. «Sexos y géneros lingüísticos». En Yo, tú... Op.cit., p. 65.

64. IRIGARAY, Luce. «El otro: mujer». En Amo a ti. Bosquejo de una felicidad en la historia. Barcelona, Icaria, 1994, pp. 101 y 100.

65. Cf. IRIgARAY, Luce. «La questione dell'altro». En La democrazia... Op.cit., pp. 116-119.

66. NicColai, Silvia. «Controversia, disciplina dell'esperienza». En A. Buttarelli y F. Giardini (comp.), op.cit., pp. 265-274.

67. ZeRILLI, Linda. Op.cit., p. 220.

Feminismo/s 15, junio 2010, pp. 75-94 
lo universal ${ }^{68}$. En razón de lo cual sostiene que «lo que los derechos piden (...) no es aceptación ciega ni rechazo sino más bien juicio político ${ }^{69}$, porque «los derechos no son cosas sino relaciones $»^{70}$.

Con este breve recorrido por algunos de los planteamientos que diversas autoras han realizado desde o próximas al pensamiento de la diferencia sexual, trato, simplemente, de dar cuenta de la riqueza de la discusión, lo que quizás podría abrir nuevas perspectivas o poner en juego elementos de debate.

Considero que las autoras con las cuales he intentado pensar a lo largo de este artículo nos invitan a reflexionar con radicalidad sobre cuáles sean las mediaciones a poner en juego para dar existencia social y simbólica a las mujeres. Estimo que las preguntas que plantean acerca de la eficacia de la ley, la centralidad del derecho y la «tensión ineliminable», en palabras de Zerilli, entre la representación política que los derechos aseguran y la libertad son preguntas vivas y chispeantes. Vivas y chispeantes porque son auténticas preguntas, es decir, aquéllas para las que no tenemos respuestas o a las que no podemos responder a priori, sino que solicitan de nosotras pensamiento. Entre otras cuestiones de profundo calado, las pensadoras de la diferencia sexual insisten, y con razón, en mostrar «los límites de un principio de igualdad que no forma parte de una práctica de libertad ${ }^{71} \mathrm{y}$ en señalar que la igualdad jamás podrá satisfacer la libertad ${ }^{72}$. Así, el significado y las posibilidades de la libertad femenina se presentan, desde mi punto de vista, como uno de los nudos de conflicto del feminismo contemporáneo.

\section{Apostar por los conflictos, apostar por la creatividad}

Para finalizar, quisiera abordar, sucintamente, una de las preguntas que el comité de la revista planteaba en la petición de contribuciones para este número: la pertinencia de mantener o, por el contrario, superar la distinción

68. Cf. Ibíd., pp. 219 y ss. Para la interpretación de Zerilli de este concepto: cf. Ibíd., pp. 239-309. Para la noción de juicio en Hannah Arendt: ARENDT, Hannah. Conferencias sobre la filosofía política de Kant. Barcelona, Paidós, 2003 y La vida del espíritu. Barcelona, Paidós, 2002.

69. Ibid., p. 238.

70. Ibid., p. 235.

71. Ibíd., p. 237.

72. Cf. Ibíd., p. 235, nota 52. La presencia contemporánea de la libertad en el feminismo me conduce a considerarlo como uno de los nudos de conflicto. Zerilli así lo apunta, apostando por un «feminismo centrado en la libertad». En este sentido interpreto, por ejemplo, la obra de Judith Butler: cf. BuRGOS, Elvira. Qué cuenta como una vida. La pregunta por la libertad en Judith Butler. Madrid, Antonio Machado, 2008. O la reciente lectura de Kristeva de la herencia beauvoiriana: cf. KRISTEVA, Julia. «Beauvoir aux risques de la liberté». http://www.kristeva.fr/Beauvoir.html, consultado el 26-02-2010. 
entre feminismo de la igualdad y de la diferencia. Considero necesario revisar estas macrocategorías con el propósito de no convertirlas en tristes etiquetas ni en burdas caricaturas ni, menos aún, en armas arrojadizas; puesto que en el «interior» de ambas corrientes habita una gran diversidad que corre el riesgo de ser terriblemente reducida o simplificada por el uso aproblemático de tales categorías omniabarcantes. Si bien éstas no son las únicas corrientes del feminismo (pienso, por ejemplo, en la emergencia, desde la década de los noventa, del feminismo queer), ambas han articulado y continúan articulando buena parte de la discusión. Por esta razón, encuentro en la pregunta mencionada una ocasión para repensar tales categorías con el objeto no de clausurarlas, sino de reabrirlas y ponerlas constantemente en juego junto con nuestra lectura (la de cada una) de una realidad cambiante. Esto no significa, sin embargo, ignorar los conflictos entre nuestras distintas lecturas, sino, más bien, apostar por ellos: apostar por la riqueza y la creatividad que los conflictos pueden poner en movimiento.

Me preocupa que el deseo de superación de la distinción (contenido, de alguna manera, en la pregunta) exprese o indique un deseo de superación de los conflictos, un intento de saltar por encima de ellos en lugar de atravesarlos, de abordarlos; en suma, de ponerlos en juego. Como bien ha señalado la filósofa italiana Luisa Muraro, entre otras, «los conflictos no son las guerras ${ }^{73}$ ni tampoco la dialéctica, que, a mi juicio, es la lógica de la guerra llevada a la lógica del discurso. Los conflictos demandan de nosotras apertura y creatividad.

A mi modo de ver, los conflictos en el feminismo han constituido la vida misma del feminismo, al menos, desde su resurgimiento contemporáneo a finales de la década de los sesenta. Y considero que continúan siendo su horizonte. Tal y como Diana Sartori ha afirmado «reconocer el feminismo como esfera pública, como espacio político, como mundo significa mirar con realismo a las diferencias y a los conflictos que lo animan y lo sustancian ${ }^{74}$. La dificultad reside en que se conviertan en barreras que impidan el intercambio y la apuesta consiste en considerarlos una oportunidad en vez de un lastre. Creo, sinceramente, que los conflictos forman parte de la vida del feminismo. Son, justamente, un signo de vitalidad, de apertura al presente y promesa de futuro.

73. Muraro, Luisa. «Feminismo...» Op.cit., p. 46. Acerca de los conflictos actuales en el feminismo: cf. los dossiers «Il taglio del conflitto. Dove passa la linea dei conflitii nel feminismo?», per amore del mondo, otoño 2006 y «Un certain regard», per amore del mondo, primavera 2008. Op.cit.

74. SARTORI, Diana. «Il taglio del conflitto...» Op.cit.

Feminismo/s 15, junio 2010, pp. 75-94 


\section{Referencias bibliográficas}

Collin, Françoise. «De l'échange des femmes à l'échange entre femmes». per amore del mondo, primavera 2008, <http://www.diotimafilosofe.it/riv_online. php>, consultado el 19-01-2009.

BRAIDOTTI, Rosi. Transposiciones. Sobre la ética nómada. Barcelona, Gedisa, 2009 (orig. 2006).

ButTARELli, Annarosa y GiARdini, Federica (comp.). Il pensiero dell'esperienza. Milán, Baldini Castoldi Dalai, 2008.

Diótima. La sapienza di partire da sé. Nápoles, Liguori, 1996.

IRIGARAY, Luce. Speculum. Espéculo de la otra mujer. Madrid, Saltés, 1978 (orig. 1974).

- Ese sexo que no es uno. Madrid, Saltés, 1982 (orig. 1977).

- El cuerpo a cuerpo con la madre. El otro género de la naturaleza. Otro modo de sentir. Barcelona, La Sal, 1985 (orig. 1981).

- Yo, tú, nosotras. Madrid, Cátedra, 1992 (orig. 1990)

- Amo a ti. Bosquejo de una felicidad en la historia. Barcelona, Icaria, 1994 (orig. 1992).

- La democrazia comincia a due. Turín, Bollati Boringhieri, 1994.

- «De Speculum a Entre Oriente y Occidente. Luce Irigaray, 25 años de filosofía feminista de la diferencia. Entrevista». Triple Jornada, La Jornada, 2 de agosto de 1999. En <www.jornada.unam.mx/1999/08/02/irigaray.htm>, consultado el 15-04-2007.

LIBRERÍA DE MUJERES DE MILÁN. No creas tener derechos. La generación de la libertad femenina en las ideas y vivencias de un grupo de mujeres. Madrid, horas y HORAS, 2004 (orig. 1987).

- La cultura patas arriba. Selección de la Revista Sottosopra 1973-1996. Madrid, horas y HORAS, 2006.

Muraro, Luisa. «Feminismo y política de las mujeres». Duoda, 28 (2005), pp. 39-47.

RICH, Adrienne. Sobre mentiras, secretos y silencios. Barcelona, Icaria, 1983 (orig. 1979)

SARTORI, Diana. «Libertad «con». La orientación de las relaciones». Duoda, 26 (2004), pp. 105-115.

— «Il taglio del conflitto. Dove passa la linea dei conflitii nel feminismo?» per amore del mondo, otoño 2006, <http://www.diotimafilosofe.it/riv_online. php>, consultado el 25-05-2007.

VAlCÁrCEl, Amelia (comp.). El concepto de igualdad. Madrid, Pablo Iglesias, 1994. ZeRILLI, Linda. El feminismo y el abismo de la libertad. Buenos Aires, FCE, 2008 (orig. 2005). 